\title{
SALMO 1 - TRADUÇÃO, COMPARAÇÃO E PRÉVIA EXEGESE
}

\author{
Ricardo Lopes Firmino ${ }^{1}$
}

\begin{abstract}
Resumo
O tema "Salmo 1 - Tradução, Estudo Comparativo e Breve Exegese" parte da necessidade e raridade de comentários nos Salmos em Língua Portuguesa a partir do texto em hebraico, bem como um estudo comparativo com outras traduções e versões já existentes, seja em Língua Portuguesa, Espanhola ou Inglesa. Em adição, tem como objetivo analisar o texto em hebraico do Salmo 1, fazer uma breve exegese e comparar com outras versões já existentes. Simultaneamente, far-se-á breves comentários de acordo com visão de outros autores que tem se dedicado ao estudo esmerado desses salmos. Tratase de um tema de grande relevância na sociedade acadêmica e comunidade em geral que precisa entender este Salmo a partir de um estudo mais acurado, voltado não apenas para a acadêmicos de Teologia, mas também para exegetas e intérpretes que dedicam-se ao exame profundo do texto dos saltérios. O Salmo 1 contém uma riqueza de informações de grande relevância para os que se dedicam ao ensino teológico, e mesmo ao ministério da pregação bíblica. Por conseguinte, a fim de fundamentar nosso trabalho, consultamos os vários teóricos que dedicam-se aos estudos dos textos bíblicos em hebraico como Harris (1999), Davidson (2018), Chaves (11997), Holladay (2010) e Schökel (1997). A metodologia aplicada será o método científico dialético. Já o procedimento técnico se baseia na pesquisa bibliográfica, valendo-se do critério de comparação de literaturas similares, e estudos adquiridos na formação acadêmica.
\end{abstract}

Palavras-Chaves: hebraico; tradução; salmo; exegese.

\footnotetext{
${ }_{1}^{1}$ Pesquisador independente. Formação - Bacharel em Teologia (FATIN, 2013), Licenciatura Plena em Pedagogia (FAK, 2014), Licenciatura Plena em Letras (UNINILTONLINS, 2017), Especialista (Lato Sensu) em Ciências da Religião (FAK, 2014), Docência do Ensino Superior (FTP, 2015), Teoria Psicanalítica Aplicada (FTP, 2015), Cultura e Literatura (FESL, 2017), Orientação, Supervisão e Inspeção Escolar (Gestão, FESL, 2018), Maçonologia: História e Filosofia (UNINTER, 2019), Língua Portuguesa: Redação e Oratória (em andamento - FAEL). Ministro de Confissão Religiosa, Professor de diversas disciplinas teológicas na Faculdade Teológica Missão Macedônia (FATEMMA) e no Seminário Teológico Batista da Amazônia (STBA) e Professor Ensino Religioso na Rede Municipal de Ensino (SEMED-Manaus) e Secretaria de Educação do Estado do Amazonas (SEDUC-AM).
} 


\section{INTRODUÇÃO}

O tema "Salmo 1 - Tradução, Estudo Comparativo e Breve Exegese" parte da necessidade e raridade de comentários nos Salmos em Língua Portuguesa a partir do texto em hebraico, bem como um estudo comparativo com outras traduções e versões já existentes, seja em Língua Portuguesa, Espanhola ou Inglesa.

Neste artigo, buscamos tecer algumas considerações sobre o Salmo 1, de maneira que este trabalho tem como objetivo analisar o texto em hebraico do dito saltério, realizando uma breve exegese e comparação com outras versões já existentes. Simultaneamente, far-se-á breves comentários de acordo com a visão de outros autores que tem se dedicado ao estudo esmerado desses cânticos hebraicos.

Trata-se de um tema de grande relevância na sociedade acadêmica de estudos teológicos e comunidade religiosa em geral que precisa entender este Salmo a partir de um estudo mais acurado, voltado não apenas para a acadêmicos de Teologia, mas também para exegetas e intérpretes que dedicam-se ao exame profundo do texto dos sacros cânticos da Bíblia Hebraica.

O Salmo 1 contém uma riqueza de informações de grande relevância para os que se dedicam ao ensino teológico, e mesmo ao ministério da pregação bíblica.

Por conseguinte, a fim de fundamentar nosso trabalho, consultamos os vários teóricos que dedicam-se aos estudos dos textos bíblicos em hebraico como Harris (1999), Davidson (2018), Chaves (11997), Holladay (2010) e Schökel (1997).

A metodologia aplicada será o método científico dialético. Já o procedimento técnico se baseia na pesquisa bibliográfica, valendo-se do critério de comparação de literaturas similares, e estudos adquiridos na formação acadêmica. 


\section{O SALMO 1 COMO INTRODUÇÃO A TODOS OS SALMOS}

2. 1 Salmo 1 - Bíblia Hebraica Stuttgartensia (BHS) e Bíblia Sagrada (BCF - Corrigida Fiel).

Neste trabalho, usar-se-á a Bíblia Hebraica Stuttgartensia² para busca e referência do texto bíblico em hebraico, visto ser o texto mais usado nas traduções ou artigos em que se trabalha as translações dos textos do Antigo Testamento ${ }^{3}$. Quanto à Bíblia Sagrada versão Corrigida Fiel, diz respeito ao seu uso comum entre cristãos de fala portuguesa.

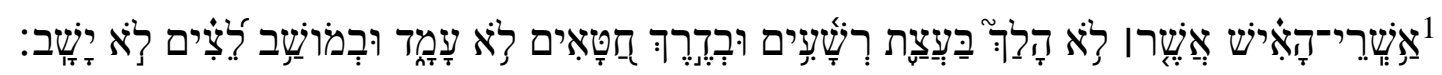

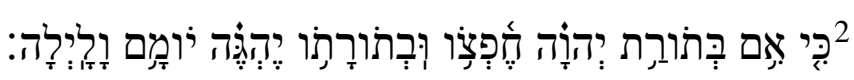

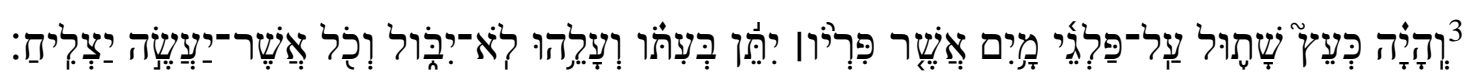

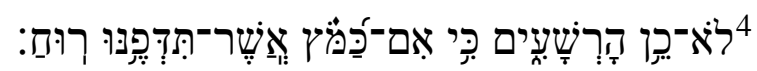

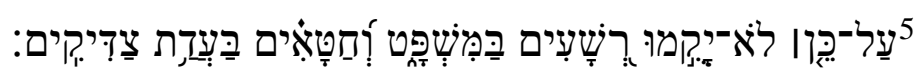

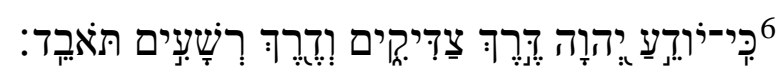

${ }^{1}$ Bem-aventurado o homem que não anda segundo o conselho dos ímpios, nem se detém no caminho dos pecadores, nem se assenta na roda dos escarnecedores.

${ }^{2}$ Antes tem o seu prazer na lei do Senhor, e na sua lei medita de dia e de noite.

${ }^{3}$ Pois será como a árvore plantada junto a ribeiros de águas, a qual dá o seu fruto no seu tempo; as suas folhas não cairão, e tudo quanto fizer prosperará.

${ }^{4}$ Não são assim os ímpios; mas são como a moinha que o vento espalha.

${ }^{5}$ Por isso os ímpios não subsistirão no juízo, nem os pecadores na congregação dos justos.

${ }^{6}$ Porque o Senhor conhece o caminho dos justos; porém o caminho dos ímpios perecerá.

\footnotetext{
${ }^{2}$ Doravante neste trabalho representada pela sigla BHS.

${ }^{3}$ Neste trabalho se usará a sigla AT.
} 
O Salmo 1 é um elogio à Torah, à Lei sapiencial ${ }^{4}$.

O Salmos 1:1-6 tem uma estrutura que pode ser assim esboçada:

$\checkmark$ vv. 1-2 duas fontes contrastantes de orientação: a metáfora da "jornada";

$\checkmark$ vv. 3-4 duas consequências contrastantes: metáfora da "planta";

$\checkmark$ vv. 5-6 dois resultados finais contrastantes $(T M)^{5}$.

Que, segundo Kartje (2014, p. 75),

A característica estrutural dominante do salmo é a comparação antitética entre o homem abençoado e o ímpio. O primeiro dístico define a distinção entre os dois modos de vida, o segundo dístico desenvolve as qualidades que caracterizam cada caminho, enquanto o terceiro dístico descreve o destino final para o qual cada caminho leva $(\mathrm{TM})^{6}$.

O Salmo 1, portanto, trata da responsabilidade do homem, perante o Sagrado, o próximo e perante si mesmo, esclarecendo as consequências das decisões do ser humano, sejam essas decisões corretas ou erradas.

\section{TRADUÇÃO E BREVE EXEGESE DO SALMO 1}

\section{1 Verso 1}

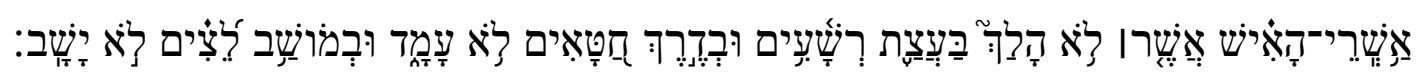
(asherê ha-ish ashêr lô halache baêtzath re ${ }^{e}$ shaím uvedêrêche chataiym lô amad uvemoshav lêtziym lô yashav).

Numa leitura bem direta, pode-se escrever uma tradução condensada desta forma:

Bendito (abençoado, feliz, bem-aventurado, ditoso) é o homem (o esposo, o varão) que não caminha (passeia de ida e volta, anda, se move, anda sobre, vive o modo

\footnotetext{
${ }^{4}$ RÖSEL, 2009.

${ }^{5}$ Tradução Minha das palavras:

vv. 1-2 two contrasting sources of guidance: "journey" metaphor

vv. 3-4 two contrasting consequences: "plant" metaphor

vv. 5-6 two contrasting final outcomes

${ }^{6}$ Tradução Minha das palavras: [...] The psalm's dominant structural feature is the antithetical comparison between the blessed man and the wicked. The first couplet defines the distinction between the two ways of life, the second couplet develops the qualities that characterize each way, while the third couplet describes the ultimate destination toward which each way leads [...].
} 
de vida - sentido figurado) no conselho (propósito) dos maus (dos criminosos, dos culpados de pecado contra Deus e o homem, de alguém que comete crime, dos ímpios, dos hostis a Deus) e no caminho (na senda, na estrada, nos hábitos, nos modos, no curso da vida, no caráter) dos pecadores (reconhecidos como infratores, expostos à condenação) permanece (se detém, torna-se um servo de) e na roda (no assento, na assembleia, na habitação, em companhia, no local de reunião) dos que escarnecem (dos que zombam) não se assenta.

\section{1. 1.}

O Salmo 1 tem sido, geralmente entre acadêmicos, classificado como um salmo de sabedoria ou um salmo da Torá ${ }^{7}$, como sugerido já em sua abertura com a

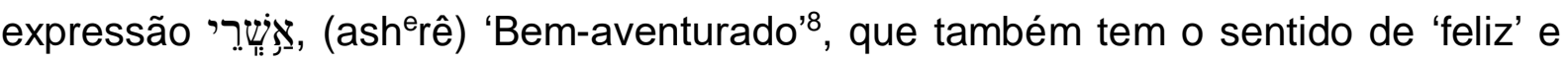
'abençoado'9.

Nas palavras de Ross (2011, p. 182)

[...] é um termo que se refere à condição espiritual de gozo daqueles que são justos para com Deus e o prazer e a satisfação que deriva disso. É um abstrato plural, enfatizando a plenitude da alegria [...] Esta palavra se refere a esse sentimento de alegria e satisfação que vem com o conhecimento de que se está bem com Deus, independente do que aconteça $\left(\mathrm{TM}^{10}\right)$.

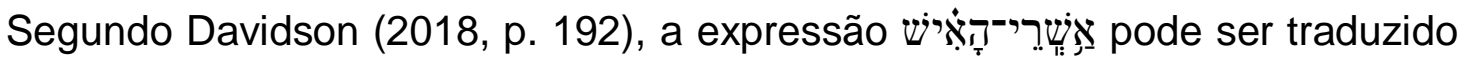
como uma interjeição 'Oh, a felicidade do homem? . Nas palavras de Harris et al (1998, p. 135)

[...] para ser "abençoado" (ashrê), o homem tem que fazer algo. Normalmente se trata de algo feito de modo positivo. Um homem "abençoado", por exemplo, é alguém que confia em Deus inteiramente: Salmos 2.12; 34.8[9]; 40.4[5]; 84.5[6]; 84.12[13]; 146.5; Provérbios 16.20. Um homem "abençoado" é aquele que se coloca sob a autoridade da revelação de Deus: a sua Torá (SI 119.1; 1.2; Pv 29.18); a sua palavra (Pv 16.20); os seus mandamentos (SI 112.1); o seu testemunho (SI 119.2); o seu caminho (SI 128.1; Pv 8.32). O

\footnotetext{
${ }^{7}$ FIRTH; JOHNSTON, 2005

${ }^{8}$ DAY, 1990, Pg. 55

${ }^{9}$ HOLLADAY, 2010, pg. 41.

${ }^{10}$ Tradução Minha das palavras: [...] a term that refers to the joyful spiritual condition of those who are right with God and the pleasure and satisfaction that is derived from that. It is an abstract plural, stressing the fullness of joy [...] This word refers to that sense of joy and satisfaction that comes with knowing that one is right with Godin spite of what happens [...]
} 
homem benigno para com o pobre é abençoado (Salmo 41.1[2]; Pv 14.21) $[\ldots]$.

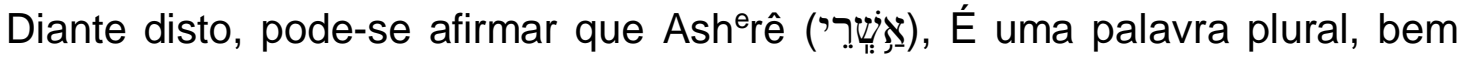
como a primeira palavra do Salmo 1, e também a abertura de todos os salmos da Bíblia Hebraica. Para Prévost (1991, p. 22)

[...] é de fato, em hebraico, um nome plural [...] é a primeira palavra do saltério, e não somente do SI 1, como se quisesse fazer dela a porta de entrada do mundo dos salmos [...] para entrar nesse mundo, é preciso estar sedento de felicidade. O saltério é antes de tudo boa nova para todos esses pobres que buscam tal felicidade através de todas as situações da vida, inclusive difíceis, trágicas e espantosas, que o saltério evoca $\left(\mathrm{TM}^{11}\right)$.

No primeiro verso, é feito uma descrição sumária sobre a vida do justo. Como já supracitado, o Salmo 1 começa com um anúncio do estado espiritual que qualifica o homem como alguém feliz, abençoado ou bem-aventurado.

Ou seja, de acordo com o salmista, o caminho da felicidade e da bênção pode

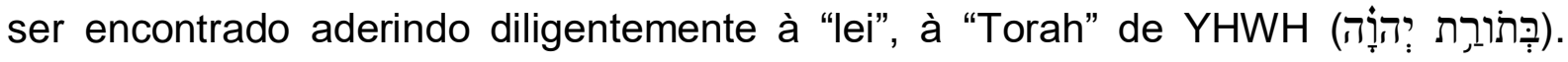
Contudo, a Torah, doravante, mencionada neste Salmo, não se trata da Lei que costumamos associar à Bíblia Hebraica - o conjunto de regras dadas por YHWH aos israelitas em Êxodo e Levítico.

Neste caso, especificamente, a Torah é um conceito positivo tanto para o autor do Salmo 1 como à comunidade da fé que o cantava ao cultuar $\mathrm{YHWH}^{12}$. Sabe-se que, no sentido literário, Torah se refere aos cinco primeiros livros da Bíblia, conhecidos como Pentateuco, a história do antigo Israel, bem como às leis outorgadas a eles - uma tradução melhor para termo seria instrução. Neste caso, para os antigos israelitas, a Torah era toda a memória da ação divina em suas vidas, que incluía a Torah oral, a tradição comunicada pelo pais.

Assim, havia a Torah escrita e a Torah oral que, segundo Lenhardt e Collin (1997, p. 9)

\footnotetext{
${ }^{11}$ Tradução Minha do texto: [...] es de hecho, en hebreo, un nombre plural [...] es la primera palabra del saltério, y no sólo del Sal 1, como si se hubiera querido hacer de ella la puerta de entrada al mundo de los salmos [...] Para entrar en esse mundo, hay que estar sediento de felicidad. El saltério es ante todo buena nueva para todos esos pobres que buscan la dicha a través de todas las situaciones de la vida, incluso difíciles, trágicas y espantosas, que evoca el saltério.

${ }^{12}$ Neste trabalho, doravante, refere-se ao Senhor, a Yaweh, ao Eterno, ao deus dos hebreus ou israelitas.
} 


\begin{abstract}
A Torah, a Palavra de Deus que os mestres fariseus ensinam ao povo de Israel, já antes do tempo do Novo Testamento, não é apenas a Escritura, a Torah escrita. Compreende também, e antes de tudo, a Tradição que deve ser denominada Torah oral. A oralidade da Tradição é a de uma palavra que é, na origem, recebida de Deus, que dá e alimenta a vida. O campo da oralidade não se reduz, pois, ao que é dito pela boca e escutado pelo ouvido; estende-se a toda experiência de vida [...] De fato, a Torah oral é, por si mesma, anterior e exterior à Escritura, e independente da Escritura que ela recebe, engloba e interpreta.
\end{abstract}

Ou seja, para o judaísmo ortodoxo, o ensinamento, instrução, a interpretação dada pelos pais (avôt), pelos mestres antigos, depois de examinada e discutida, é tão inspirada quanto a Palavra Escrita. A ponto de chegarem ao exagero de, numa tradição bíblica, serem acusados pelo mestre de invalidar a palavra escrita por causa de seu apego à tradição dos anciãos ${ }^{13}$.

Deste modo, com o passar dos anos, houve a necessidade de reorganizar a Torah oral em torno ou a partir de uma coletânea de tradições canonizadas, que passou a ter autoridade sobre os judeus ortodoxos, tendo um especial valor para ser usada como referência. A essa, coletânea foi dada o nome de Mishnah (coisas estudadas e ensinadas por repetição. A repetição das tradições relativas a todos os campos da vida judaica (LENHARDT; COLLIN, 1997).

Assim, דָהָיש (ha-ish) descreve sempre o homem no sentido próprio, e diferenciado da mulher ${ }^{14}$, o esposo ${ }^{15}$, o varão, alguém de excelentes qualidades morais. Às vezes, significa o homem em geral' ${ }^{16}$ (BERZOSA, 2014).

Também, pode ser masculino, herói, todos, alguém, qualquer um (KLEIN, 1987, p. 26).

Segundo Harris et al. (1998, p. 62), o termo w'. (ish) pode ser "homem, espécie humana, vencedor, grande homem, marido, pessoa, todo o que".

Da mesma forma, para Davidson (2018, p. 158) pode ser, na ordem: I) homem [...] II) marido [...] III) homem, em oposição a Deus e animais [...].

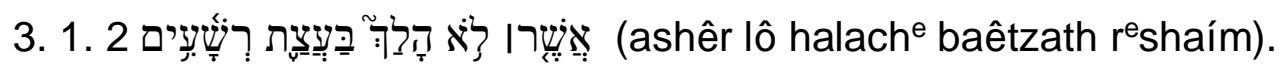

\footnotetext{
${ }^{13}$ Marcos 7.1-13

${ }^{14} 1$ Samuel 17.33

${ }^{15}$ Gênesis 3.16; Oséias 2.16

${ }^{16}$ Êxodo 16.29
} 
O termo que. ל̧ (lô) ${ }^{18}$ pode ser traduzido como 'não', ou seja, é uma negação declarativa comum. Da mesma forma, a palavra (halache ${ }^{19}$ tem o sentido de ir, andar. Na

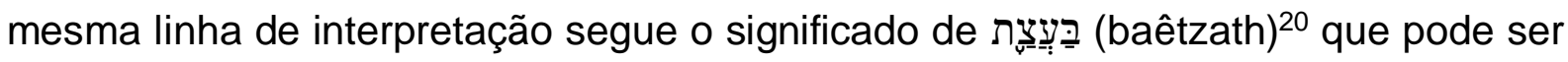

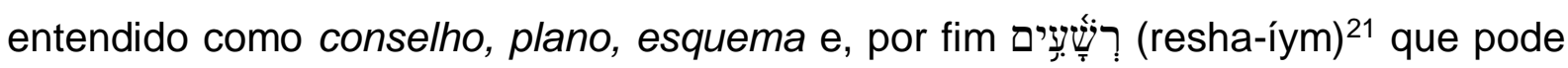
ser traduzido como ímpios, incrédulos, perversos.

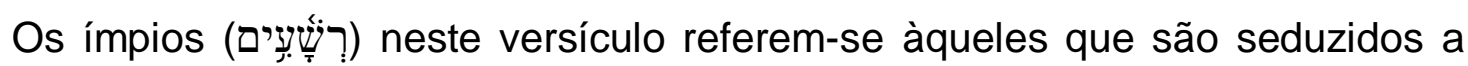
seguir o conselho de alguém que é mau, daí porque são seduzidos a seguir por um caminho com o qual não estão familiarizados. Sendo que a palavra, basicamente, descreve pessoas que não são membros da aliança, não crentes e, portanto, ímpias. Assim, a ideia principal é que, como eles não creram no Senhor e não encontraram perdão por seus pecados, eles são condenados como culpados e merecedores do castigo divino 22 .

A palavra, também, pode descrever pessoas que podem parecer gentis, fazendo parte da congregação, entretanto, eles simplesmente não são piedosos, pois

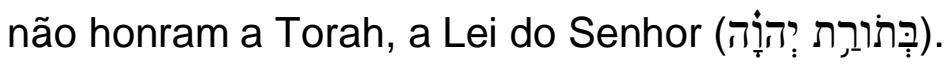

Ou seja, que

"Feliz é o homem que não caminha aconselhado por perversos ${ }^{23}[\ldots]$ ".

"Feliz o homem que não toma o partido dos maus ${ }^{24}[. .]$.$" .$

"Feliz o homem que não vai ao conselho dos ímpios ${ }^{25}[. .]$.$" .$

"Bienaventurado el varón que no anduvo em consejo de malos ${ }^{26}[. .$.$] ".$

"Blessed is the man that walketh not in the counsel of the ungodly ${ }^{27}[\ldots]$ ".

\footnotetext{
17 DAVIDSON, 2018.

18 HOLLADAY, 2010.

19 HARRIS et al, 1998, p. 355.

${ }^{20}$ HOLLADAY, 2010, p. 397.

21 DAVIDSON, 2018, p. 997.

22 FIRTH; JOHNSTON, 2005.

${ }^{23}$ BÍBLIA - Bíblia do Peregrino. Comentário de Luís Alonso Schökel. 2 ed. - São Paulo: Paulus, 2006.

${ }^{24}$ BÍBLIA - Bíblia Tradução Ecumênica. São Paulo: Edições Loyola, 1994.

${ }^{25}$ BÍBLIA - Bíblia de Jerusalém. São Paulo: Paulus, 1990.

${ }^{26}$ BÍBLIA (em Espanhol) - La Santa Bíblia: Edición de Promesas. Miami, Florida: EDITRIAL UNILIT, 1994.

${ }^{27}$ BÍBLIA (em Inglês) - Comparative Study Bible - King James Version (KJV).
} 
"Blessed (HAPPY, fortunate, prosperous, and enviable) is the man who walks and lives not in the counsel of the ungodly (following their advice, their plans and purpose $)^{28}[\ldots] "$.

"How blessed is the man who does not walk in the counsel of the wicked ${ }^{29}[. .$.$] .$

Ao mesmo tempo que o salmista exorta exalça como bem-aventurado o que se deleita na Torah, também desvela os perigos de se fazer o contrário, mostrando sempre os dois lados da moeda, da obediência à Tradição.

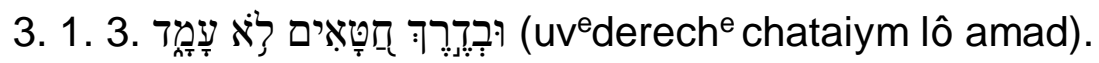

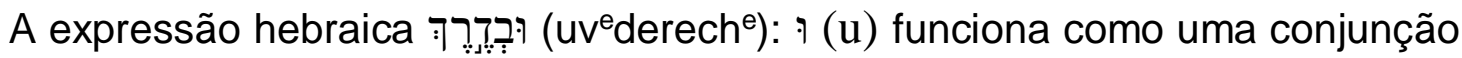
aditiva 'e'; جִ ( $\left.v^{e}\right)$ é uma preposição como em+o(a), que forma 'no' (na); e (dêrekhe $)^{30}$, que tem o sentido de caminho, trilha. Já a palavra (chataíym) ${ }^{31}$ tem o sentido de pecadores, pecaminosos - designa um pecador contumaz que é sujeito

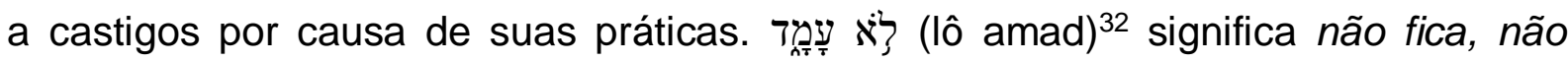
permanece, não fica em, não se estabelece.

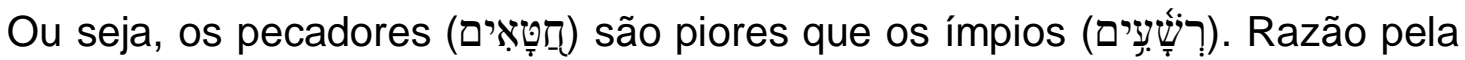
qual as Escrituras falam do 'caminho dos pecadores'. Acredita-se que os pecadores costumam andar de maneira má. Eles voluntariamente andam na senda do engano ${ }^{33}$.

Contudo, o justo

"[...] no caminho dos pecadores, não se detém ${ }^{34}$ [...]".

"[...] não pára no caminho dos pecadores ${ }^{35}[\ldots]$...

“[...] Ni estuvo em caminho de pecadores ${ }^{36}[\ldots]$.

"[...] nor stands [submissive and inactive] in the path where sinners walk ${ }^{37}[\ldots]$.

"[...] Nor stand in the path of sinners ${ }^{38}$ [...].

\footnotetext{
${ }^{28}$ BÍBLIA (em Inglês) - Comparative Study Bible - Amplified Bible (AMP).

${ }^{29}$ BÍBLIA (em Inglês) - Comparative Study Bible - New American Standard (NAS).

${ }^{30}$ HOLLADAY, 2010, p. 102.

${ }^{31}$ HARRIS et al, 1998, p. 452.

32 DAVIDSON, 2018, p. 885.

${ }^{33}$ FIRTH; JOHNSTON, 2005

${ }^{34}$ BÍBLIA - Bíblia do Peregrino. Comentário de Luís Alonso Schökel. 2 ed. - São Paulo: Paulus, 2006.

${ }^{35}$ BÍBLIA - Bíblia de Jerusalém. São Paulo: Paulus, 1990.

${ }^{36}$ BÍBLIA (em Espanhol) - La Santa Bíblia: Edición de Promesas. Miami, Florida: EDITRIAL UNILIT, 1994.

${ }^{37}$ BÍBLIA (em Inglês) - Comparative Study Bible - Amplified Bible (AMP).

${ }^{38}$ BÍBLIA (em Inglês) - Comparative Study Bible - New American Standard (NAS).
} 


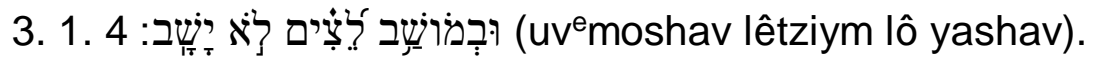

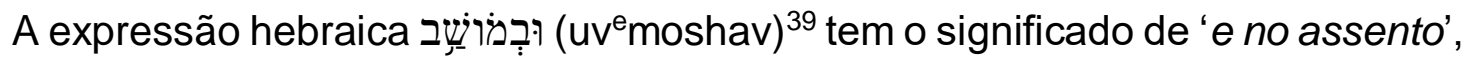
'e no lugar para se assentar', 'e no lugar', 'e na posição'. לִ (lêtziym) ${ }^{40}$ tem o sentido

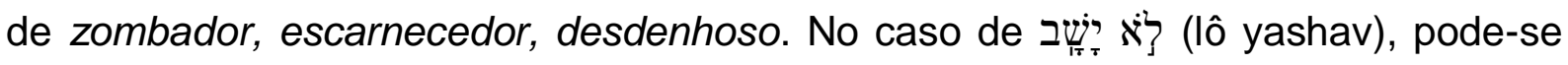
traduzir como 'não habita', 'não permanece', 'não resolve', 'não relaxa', 'não suporta', 'não se estabelece'41.

Os escarnecedores ridicularizam os justos, destruindo-lhes a integridade. Por isso, eles, os justos

"[...] na sessão dos cínicos não se assentam ${ }^{42 "}$.

"[...] não se assenta no banco dos zombadores ${ }^{43}$ ".

"[...] nem se assenta na roda dos zombadores ${ }^{44 "}$.

"[...] Ní em silla de escarnecedores se há sentado45".

"[...] nor sitteth in the seat of the scornful|46".

"[...] nor sits down [to relax and rest] where the scornful [and the mockers] gather ${ }^{47 "}$.

"[...] Nor sit in the seat of scoffers ${ }^{48}$ "

\section{2 VERSO 2}

O verso 2 do Salmo 1 assim está em hebraico:

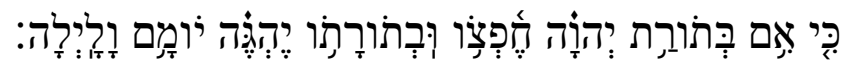

(Kí im betorat Adonay chefetzô uvetoratô yêhegeh yomam valaylah)

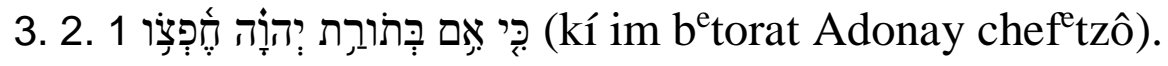

\footnotetext{
${ }^{39}$ HOLLADAY, 2010, p. 266.

${ }^{40}$ STRONG, 1990, p. 69.

${ }^{41}$ STRONG, 1990.

${ }^{42}$ BÍBLIA - Bíblia do Peregrino. Comentário de Luís Alonso Schökel. 2 ed. - São Paulo: Paulus, 2006.

${ }^{43}$ BÍBLIA - Bíblia Tradução Ecumênica. São Paulo: Edições Loyola, 1994.

${ }^{44}$ BÍBLIA - Bíblia de Jerusalém. São Paulo: Paulus, 1990.

${ }^{45}$ BÍBLIA (em Espanhol) - La Santa Bíblia: Edición de Promesas. Miami, Florida: EDITRIAL UNILIT, 1994.

${ }^{46}$ BÍBLIA (em Inglês) - Comparative Study Bible - King James Version (KJV).

${ }^{47}$ BÍBLIA (em Inglês) - Comparative Study Bible - Amplified Bible (AMP).

${ }^{48}$ BÍBLIA (em Inglês) - Comparative Study Bible - New American Standard (NAS).
} 


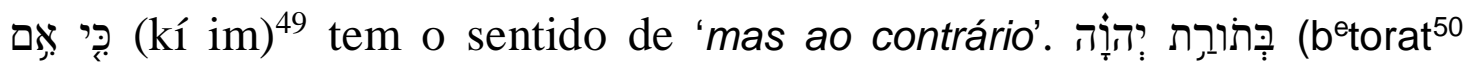
Adonay ${ }^{51}$ ) pode ser traduzido na 'instrução do Senhor', 'na Lei do Senhor'. ס̋ (chefetzố52) pode ser entendido como 'está a sua tarefa', 'está a sua dedicação', 'está a sua ocupação' ou 'está o seu assunto'.

Pode-se construir a tradução desta forma

"[...] mas ao contrário, na Lei do Senhor está a sua dedicação" [...]

"[...] mas sua tarefa é a lei do Senhor ${ }^{53}[. .$.$] "$

"[...] mas se compraz na lei do SENHOR ${ }^{54}[\ldots]$ ".

"[...] Sino que en la ley de Jehová está su delícia ${ }^{55}[\ldots]$...

"[...] But his delight is in the law of the $\operatorname{LORD}^{56}[$ [...]".

"[...] But his delight and desire are in the law of the Lord ${ }^{57}[\ldots]$ ".

"[...] But his delight is in the law of the $\operatorname{LORD}^{58}[\ldots]$...

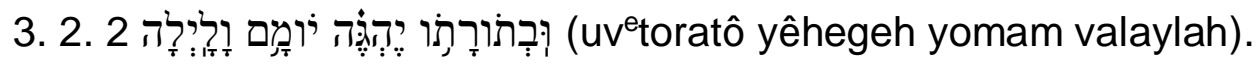

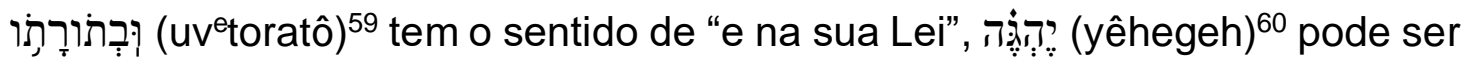
traduzido como "ele recita em voz baixa" ou "ele medita", וֹומָם (yomam $)^{61}$ pode ser "o

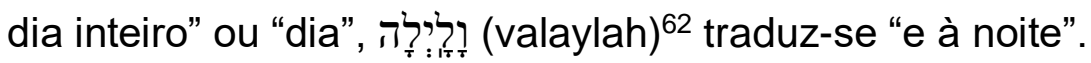

Pode-se construir a tradução desta forma "e na sua Lei, medita o dia inteiro e à noite". Fazendo uma comparação em diversas versões e traduções, lê-se:

"[...] e medita dia e noite sua lei63".

"[...] recita sua lei dia e noite ${ }^{64 "}$.

\footnotetext{
${ }^{49}$ SCHÖKEL, 1997, p. 312.

50 Ibidem, p. 700.

51 Ibidem, p. 271.

52 Ibidem, p. 238.

${ }^{53}$ BÍBLIA - Bíblia do Peregrino. Comentário de Luís Alonso Schökel. 2 ed. - São Paulo: Paulus, 2006.

54 BÍBLIA - Bíblia Tradução Ecumênica. São Paulo: Edições Loyola, 1994.

55 BÍBLIA (em Espanhol) - La Santa Bíblia: Edición de Promesas. Miami, Florida: EDITRIAL UNILIT, 1994.

${ }^{56}$ BÍBLIA (em Inglês) - Comparative Study Bible - King James Version (KJV).

${ }^{57}$ BÍBLIA (em Inglês) - Comparative Study Bible - Amplified Bible (AMP).

${ }^{58}$ BÍBLIA (em Inglês) - Comparative Study Bible - New American Standard (NAS).

59 Ibidem, p. 700.

${ }^{60}$ Ibidem, p. 166.

61 Ibidem, p. 271.

62 Ibidem, p. 343.

${ }^{63}$ BÍBLIA - Bíblia do Peregrino. Comentário de Luís Alonso Schökel. 2 ed. - São Paulo: Paulus, 2006.

${ }^{64}$ BÍBLIA - Bíblia Tradução Ecumênica. São Paulo: Edições Loyola, 1994.
} 
"[...] Y en su ley medita de día y de noche ${ }^{65 " . ~}$

"[...] and in his law doth he meditate day and night66".

"[...] and on His law (the precepts, the instructions, the teachings of God) he habitually meditates (ponders and studies) by day and by night ${ }^{67}$.

"[...] And in His law he meditates day and night68".

Trata-se de um Salmo que exalta, dignifica a Lei do Eterno, do Deus de Israel que usou seus sábios, seus anciãos, seus mestres e profetas, começando com Moisés.

Com isso, é relevante lembrar que a Torah sempre foi de grande importância para o povo de Israel. Não necessariamente a escrita, mas a mensagem, a revelação, a instrução que dela se extraía e que era, por sua vez, transmitida pelos sábios de Israel.

\section{3 VERSO 3}

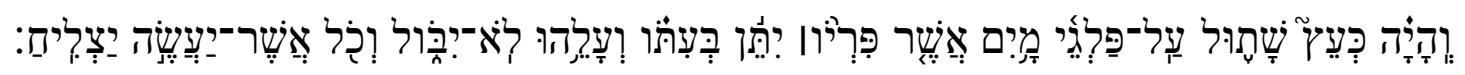

(Vehayah keêtz shatul al-pal'eguê mayim asher pireyô yiten beitô vealehu lo-yibol $v^{e} k o l$ asher-yaasseh yatzeliach).

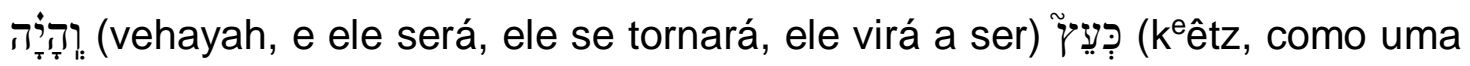

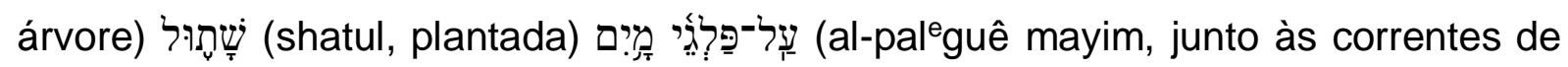

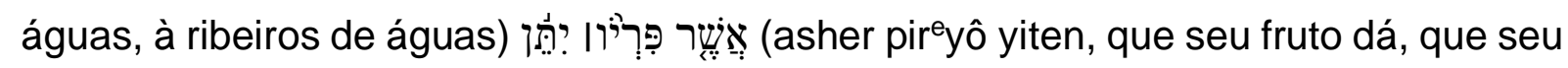

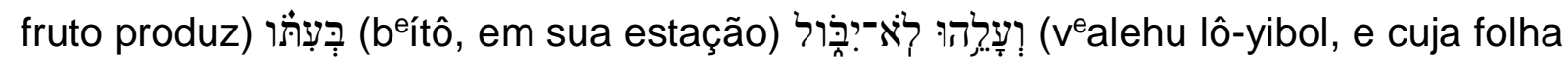

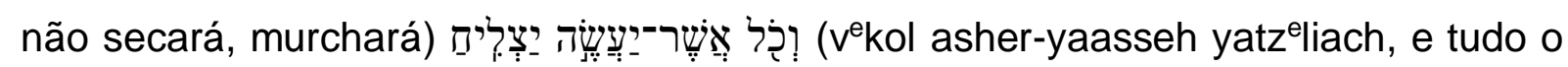
que ele fizer, prosperará) ${ }^{69}$. Pode-se ler também

"Será como árvore plantada junto aos canais, que dá fruto em sua estação, e sua folhagem não murcha. Tudo quanto faz, prospera" ${ }^{70 "}$.

\footnotetext{
${ }^{65}$ BÍBLIA (em Espanhol) - La Santa Bíblia: Edición de Promesas. Miami, Florida: EDITRIAL UNILIT, 1994.

${ }^{66}$ BíBLIA (em Inglês) - Comparative Study Bible - King James Version (KJV).

${ }^{67}$ BíBLIA (em Inglês) - Comparative Study Bible - Amplified Bible (AMP).

${ }^{68}$ BÍBLIA (em Inglês) - Comparative Study Bible - New American Standard (NAS).

${ }^{69}$ STRONG, 1990.

${ }^{70}$ BíBLIA - Bíblia do Peregrino. Comentário de Luís Alonso Schökel. 2 ed. - São Paulo: Paulus, 2006.
} 
"Ele é como uma árvore plantada junto a regatos: produz fruto na estação devida e sua folhagem não murcha; ele tem êxito em tudo o que faz ${ }^{71 " .}$.

"Será como árbol plantado junto a corrientes de águas, que dá su fruto en su tempo, y su hoja no cae, y todo lo que hace prosperará72".

"And he shall be like a tree planted by the rivers of water, that bringeth forth his fruit in his season; his leaf also shall not wither; and whatsoever he doeth shall prosper" ${ }^{73 "}$.

"And he shall be like a tree firmly planted [and tended] by the streams of water, ready to bring forth its fruit in its season; its leaf also shall not fade or wither; and everything he does shall prosper [and come to maturity] ${ }^{74 "}$.

"He will be like a tree firmly planted by streams of water, Which yields its fruit in its season And its leaf does not wither; And in whatever * he does, he prospers ${ }^{75}$ ".

Neste verso, o salmista trata de mostrar os benefícios de ser fiel, de ser fervorosamente fiel à essa tradição outrora comunicada pelos antigos sábios de Israel.

\section{4 VERSO 4}

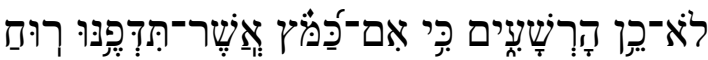

(Lô-chen hareshaiym ki im-kamôtz asher-tidefenu ruach).

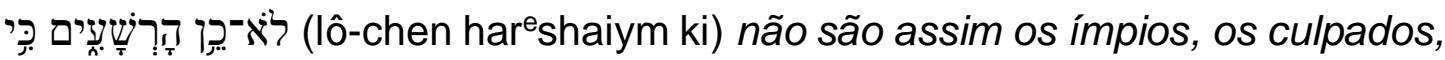

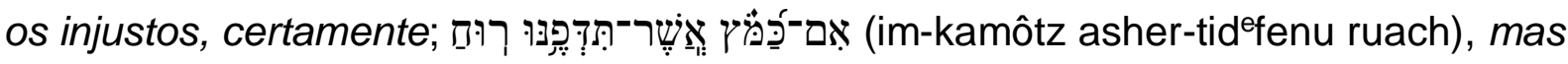
são como palha (feno, pó, restos da lã ou da seda) que o vento espalha ${ }^{76}$. Pode-se assim ler

"Não é assim com os perversos: são como palha que o vento arrebata7"

"Diferente é a sorte dos maus: são como a palha que o vento dispersa"

"No así los malos, que son como el tamo que arrebata el viento79".

\footnotetext{
${ }^{71}$ BÍBLIA - Bíblia Tradução Ecumênica. São Paulo: Edições Loyola, 1994.

72 BÍBLIA (em Espanhol) - La Santa Bíblia: Edición de Promesas. Miami, Florida: EDITRIAL UNILIT, 1994.

${ }^{73}$ BÍBLIA (em Inglês) - Comparative Study Bible - King James Version (KJV).

${ }^{74}$ BÍBLIA (em Inglês) - Comparative Study Bible - Amplified Bible (AMP).

${ }^{75}$ BÍBLIA (em Inglês) - Comparative Study Bible - New American Standard (NAS).

${ }^{76}$ CHAVEZ, 1997.

${ }^{77}$ BÍBLIA - Bíblia do Peregrino. Comentário de Luís Alonso Schökel. 2 ed. - São Paulo: Paulus, 2006.

78 BÍBLIA - Bíblia Tradução Ecumênica. São Paulo: Edições Loyola, 1994.

${ }^{79}$ BÍBLIA (em Espanhol) - La Santa Bíblia: Edición de Promesas. Miami, Florida: EDITRIAL UNILIT, 1994.
} 
"The ungodly are not so: but are like the chaff which the wind driveth away80". "Not so the wicked [those disobedient and living without God are not so]. But they are like the chaff [worthless, dead, without substance] which the wind drives away81". "The wicked are not so, But they are like chaff which the wind drives away ${ }^{82 "}$.

\section{5 VERSO 5}

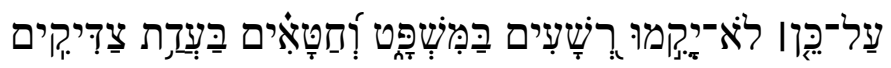

(al-chen lô-yakimu reshayim bamishaiym v ${ }^{\mathrm{e}}$ chataiym baadath tzadiqim)

עַל־ֵָּּ (Iô-chen), pode ser traduzido como por isso, por esse motivo, por essa razão, à vista disso, em razão disso, isto posto, dado isto; לאיאיקמי (lô-yakumu), que pode ser 'não se levantarão', 'não se erguerão', 'não surgirão', 'não aparecerão', 'não

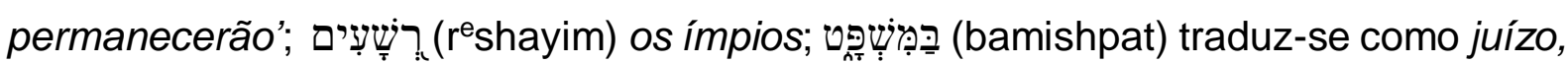

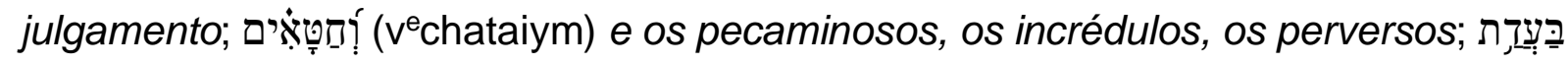
(baadat) na congregação, no ajuntamento; (tzadiqim) dos justos, dos retos ${ }^{83}$.

"Por isso, os perversos no julgamento não ficarão de pé, nem os pecadores na assembleia dos justos ${ }^{84 "}$.

"No dia do julgamento, os maus não ficarão de pé, nem os pecadores na assembleia dos justos ${ }^{85}$.

"Por tanto, no se levantarán los malos en el juício, ni los pecadores en la congregación de los justos ${ }^{86 "}$.

"Therefore the ungodly shall not stand in the judgment, nor sinners in the congregation of the righteous ${ }^{87 "}$.

\footnotetext{
${ }^{80}$ BÍBLIA (em Inglês) - Comparative Study Bible - King James Version (KJV).

${ }^{81}$ BÍBLIA (em Inglês) - Comparative Study Bible - Amplified Bible (AMP).

82 BÍBLIA (em Inglês) - Comparative Study Bible - New American Standard (NAS).

83 SCHÖKEL, 1997.

${ }^{84}$ BÍBLIA - Bíblia do Peregrino. Comentário de Luís Alonso Schökel. 2 ed. - São Paulo: Paulus, 2006.

${ }^{85}$ BÍBLIA - Bíblia Tradução Ecumênica. São Paulo: Edições Loyola, 1994.

${ }^{86}$ BÍBLIA (em Espanhol) - La Santa Bíblia: Edición de Promesas. Miami, Florida: EDITRIAL UNILIT, 1994.

${ }^{87}$ BÍBLIA (em Inglês) - Comparative Study Bible - King James Version (KJV).
} 
"Therefore the wicked [those disobedient and living without God] shall not stand [justified] in the judgment, nor sinners in the congregation of the righteous [those who are upright and in right standing with God] ${ }^{88 "}$.

"Therefore the wicked will not stand in the judgment, Nor sinners in the assembly of the righteous ${ }^{89 "}$.

\section{6 VERSO 6}

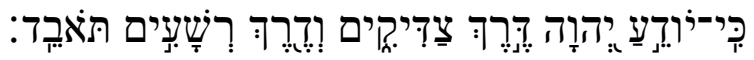

(kí-yodêa Adonay dêreche tzadyiqim ve dereche reshaym tovêd)

’ִ̣ (kí) $)^{90}$ tem o sentido de "porque, que, pois"; saber, dar a conhecer, ensinar, declarar; יהוזה (Adonay) ${ }^{92}$ o Eterno; (dêreche)

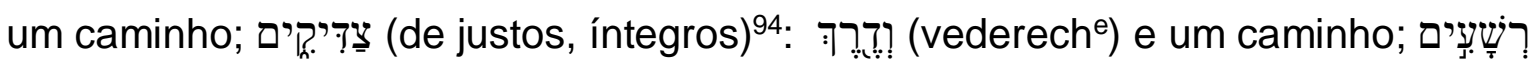
( $\mathrm{r}^{\mathrm{e}}$ shaiym) de perversos;

Fazendo as comparações de textos já traduzidos e lidos pelas comunidades religiosas, observa-se que são poucas as mudanças e organização semântica do texto.

"Porque o Senhor se ocupa dos caminhos dos justos, mas o caminho dos perversos se extravia96".

"Pois o SENHOR conhece o caminho dos justos, ao passo que o caminho dos maus se perde ${ }^{97 "}$.

"Porque Jehová conoce el caminho de los justos; mas la senda de los malos perecerá98".

\footnotetext{
${ }^{88}$ BÍBLIA (em Inglês) - Comparative Study Bible - Amplified Bible (AMP).

${ }^{89}$ BÍBLIA (em Inglês) - Comparative Study Bible - New American Standard (NAS).

${ }^{90}$ LAMBDIN, 2003, p. 375.

91 Ibidem, p. 374.

92 SCHÖKEL, 1997, p. 271.

93 KELLEY, 2015, p. 464

94 LAMBDIN, 2003, p. 379.

95 GUSSO, p. 2008, p. 305.

${ }^{96}$ BÍBLIA - Bíblia do Peregrino. Comentário de Luís Alonso Schökel. 2 ed. - São Paulo: Paulus, 2006.

97 BÍBLIA - Bíblia Tradução Ecumênica. São Paulo: Edições Loyola, 1994.

${ }^{98}$ BÍBLIA (em Espanhol) - La Santa Bíblia: Edición de Promesas. Miami, Florida: EDITRIAL UNILIT, 1994.
} 
"For the LORD knoweth the way of the righteous: but the way of the ungodly shall perish"

"For the Lord knows and is fully acquainted with the way of the righteous, but the way of the ungodly [those living outside God's will] shall perish (end in ruin and come to nought) ${ }^{100 " .}$

"For the LORD knows the way of the righteous, But the way of the wicked will perish ${ }^{101 "}$.

${ }^{99}$ BíBLIA (em Inglês) - Comparative Study Bible - King James Version (KJV).

${ }^{100}$ BíBLIA (em Inglês) - Comparative Study Bible - Amplified Bible (AMP).

${ }^{101}$ BíBLIA (em Inglês) - Comparative Study Bible - New American Standard (NAS). 


\section{CONSIDERAÇÕES FINAIS}

Estudar os Salmos é ter a experiência de haver encontrado um lençol de diamantes.

De modo que muitas lições de sabedoria para a vida podem ser extraídas deste garimpo sagrado, repleto de valiosos ensinamentos que brilham na alma do ser humano.

O trabalho aqui realizado no Salmo 1 é o ponto de partida para outros trabalhos que poderão ser de grande utilidade para a comunidade acadêmica e religiosa.

Pois, percebe-se que há uma necessidade extrema de material teológico que faça comentários e interpretação nos Salmos. Não só em forma de artigos, mas também nas aulas teológicas, onde há como fazer exegese nos Saltérios. A questão repousa na qualidade desse material, bem como a forma de utilizá-los adequadamente.

Em sua formação - nos cursos de graduação em Teologia, pouco se fala sobre os sapienciais e/ou nenhuma ênfase é dada a eles, pois é cultural que os mesmos sejam lidos como orações mágicas que exorcizam espíritos.

Em resumo, deve-se manter a opinião de que se faz necessário uma boa biblioteca teológica que enfatize os Salmos, para que os mesmos sejam explorados pelos acadêmicos e comunidade religiosa em geral, pois, com certeza, ainda há um campo bastante amplo para se explorar nessa área da Teologia. 


\section{REFERÊNCIAS}

BERZOSA, Alfonso Ropero. Gran Diccionário Enciclopédico de la Bíblia. 3 ed. Barcelona: Editorial Clie, 2014.

BÍBLIA (em Inglês) - Comparative Study Bible - King James Version (KJV), Amplified Bible (AMP), New American Standard (NAS), New International Version (NIV). Em Língua Inglesa. Grand Rapids, Michigan: Zondervan, 1999.

BÍBLIA (em Português). Bíblia Corrigida e Fiel. Sociedade Bíblica Trinitariana do Brasil, 2013.

BÍBLIA (em Português). Bíblia de Jerusalém. Nova edição, rev. e amp. 10ª impressão. - São Paulo: Paulus, 2010.

BÍBLIA (em Português). Bíblia Sagrada - Edição Pastoral. - São Paulo Paulus, 1990.

BÍBLIA (em hebraico) - Bíblia Hebraica Stuttgartensia. Sociedade Bíblica do Brasil.

BÍBLIA (em Português). Bíblia do Peregrino. Em Língua Portuguesa. Comentário de Luís Alonso Schökel. 2 ed. - São Paulo: Paulus, 2006.

BÍBLIA - Bíblia Tradução Ecumênica. Em Língua Portuguesa. São Paulo: Edições Loyola, 1994.

BÍBLIA (em Espanhol) - La Santa Bíblia: Edición de Promesas. Miami, Florida: EDITRIAL UNILIT, 1994.

CHAVEZ, Moisés. Diccionário de Hebreo Bíblico. 3 ed. - El Paso: Editorial Mundo Hispano, 1997.

DAVIDSON, Benjamin. Léxico analítico hebraico e caldaico. Tradução de Daniel de Oliveira e William Lane. - São Paulo: Vida Nova, 2018.

DAY, John. Psalms. Sheffield: JSOT Press, 1990. 
FIRTH, David; JOHNSTON, Philip S. Interpreting the Psalms: issues and approaches. Downers Grove, Illinois: Inter-Varsity Press, 2005.

GUSSO, Antônio Renato. Gramática Instrumental do Hebraico. 2 ed. rev. - São Paulo: Vida Nova, 2008.

HARRIS, R. Laird et al. Dicionário Internacional de Teologia do Antigo Testamento. Tradução Márcio Loureiro Redondo, Luiz Alberto T. Sayão, Carlos Osvaldo C. Pinto. - São Paulo: Vida Nova, 1998.

HOLLADAY, William L. Léxico hebraico e aramaico do Antigo Testamento. Tradução de Daniel de Oliveira. - São Paulo: Vida Nova, 2010.

KARTJE, John. Wisdom Epistemology in the Psalter - A Study of Psalms 1, 73, 90, and 107. Berlin/Boston: Walter de Gruyter GmbH, 2014.

KELLEY, Page H. Hebraico Bíblico: uma gramática introdutória. Tradução de Marrie Ann Wangen Krahn. 10 ed. amp. - São Leopoldo: Sinodal, EST, 2015.

KLEIN, Ernest. A Comprehensive Etymological Dictionary of the Hebrew Language for Readers of English. Jerusalem: Carta, 1987.

LAMBDIN, Thomas O. Gramática do Hebraico Bíblico. Tradução de Walter Eduardo Lisboa. - São Paulo: Paulus, 2003.

LENHARDT, Pierre; COLLIN, Matthieu. A Torah oral dos Fariseus: textos da tradição de Israel. Tradução de Nadyr de Salles Penteado. - São Paulo: Paulus, 1997.

PRÉVOST, Jean-Pierre. Diccionário de los Salmos. Navarra, España: Editorial Verbo Divino, 1991.

RÖSEL, Martin. Panorama do Antigo Testamento. Tradução de Nelson Kilpp. - São Leopoldo: Sinodal/EST, 2009.

ROSS, Allen P. Commentary on the Psalms: volume 1 (1-41). Grand Rapids: Kregel Publications, 2011. 
SCHÖKEL, Luís Alonso. Dicionário bíblico hebraico-português. Tradução: Ivo Storniolo e José Bortolini. - São Paulo: Paulus, 1997.

STRONG, James. Strong's Hebrew Exhaustive concordance of the Bible. Nashville: Thomas Nelson Publishers, 1990. 